УДК: $65.011 .42,371.68 ; 371.64 ; 004.9$

И. А. Заярная, И. П. Ковалева, С. А. Баженова, Е. В. Бородина Новороссийский филиал ФГОБУ ВО «Финансовый университет при Правительстве Российской Федерации», Новороссийск, e-mail: aiamsem@mail.ru

\title{
ЭКОНОМИЧЕСКАЯ ЭФФЕКТИВНОСТЬ ВНЕДРЕНИЯ ЭЛЕКТРОННЫХ АНАЛОГОВ УЧЕБНИКОВ В РОССИЙСКИХ ОБЩЕОБРАЗОВАТЕЛЬНЫХ ШКОЛАХ
}

Ключевые слова: цифровая экономика, экономический эффект, учебники в электронном виде, учебники на бумажном носителе, учебный процесс, общеобразовательные школы.

Авторы статьи рассматривают одну из обсуждаемых и актуальных тем нынешнего времени: эффективность внедрения электронных учебников в образовательный процесс российских школ. Существует множество зачастую противоречивых взглядов на то, что именно может дать подобное нововведение. Например, есть мнение, что переход на электронные учебники является достаточно затратным и соответственно непосильным для общеобразовательных учебных заведений мероприятием. Бытует также мнение о том, что переход на электронные учебники может отрицательно сказаться на здоровье детей из-за возрастающей нагрузки на зрительный аппарат неокрепшего, находящегося в стадии формирования организма. Поэтому приверженцы подобной точки зрения активно отрицают замену учебников в бумажном варианте на учебники в электронном формате. Отрицают подобное нововведение и некоторые преподаватели. Они высказывают опасения возможного роста нагрузки на преподавателя, из-за чего работа педагога станет непосильной.

Однако, несмотря на имеющиеся отрицания введения в образовательный процесс электронных учебников, есть и положительные отзывы, полученные в результате апробации пилотных проектов. Одним из положительных моментов является устранение существенной нагрузки на позвоночник ребенка, вынужденного носить тяжелейший ранец, в несколько раз превышающий по своему весу установленные СанПиНами нормы. Особенно эта проблема касается учащихся начальных классов. Сторонники снизить чрезмерную нагрузку на неокрепший позвоночник ребенка активно поддерживают замену тяжелых ранцев, портфелей и сумок легкими планшетами или ридерами. Помимо указанного положительного медицинского эффекта, в результате апробации, выявлены и другие положительные результаты: растущая успеваемость учащихся, повышение мотивации к обучению и пр.

Учитывая положительный социальный эффект авторы статьи рассматривают экономический эффект от внедрения в общеобразовательные школы учебников в электронном виде.

\section{Введение}

Программа «Цифровая экономика Российской Федерации» затрагивает различные сферы жизнедеятельности общества страны, в том числе и школьное образование.

В средствах массовой информации и научных трудах ученых отмечено, что на основании поправок к закону РФ об образовании все российские школы с 1 января 2015 года имеют право полного перехода на электронные учебники, что предполагает замену всех учебников на бумажных носителях одним легковесным планшетом.[1] Информатизация школьного образования позволяет решить множество проблем, среди которых тяжеловесные школьные ранцы и растущие цены на комплекты учебных пособий. Социальный эффект, неоднократно отмеченный во множестве трудов ученых и в отчетах о результатах апробации внедрения электронных учебников в образовательный процесс необходимо дополнить определением экономической эффективности подобного мероприятия.

Поскольку названному вопросу посвящено недостаточное количество работ, авторы статьи определили целью исследования выявление экономической эффективности перехода общеобразовательных школ на учебники в электронном виде.

При написании статьи использован ряд методов научного познания, а именно: метод обобщения и изучения, метод теоретического анализа и синтеза, эмпирический метод - сравнение.

\section{Результаты исследования и их обсуждение}

В рамках реализации государственной Программы «Цифровая экономика Российской Федерации» и с момента вступления в силу ГОСТа Р 57724-2017 «Информационно-коммуникационные 
технологии в образовании. Учебник электронный. Общие положения» [2] растет интерес к определению степени эффективности внедрения электронных учебников, как альтернативы бумажным учебникам.

Как показывают исследования, особенно остро стоит вопрос подобного нововведения в начальных классах общеобразовательных школ различных субъектов Российской Федерации. Растущая физическая нагрузка на позвоночник ребенка из-за превышения допустимых весовых норм ранцев учащихся вызывает серьезные опасения, как родителей, так и медицинских работников.

Результаты анкетных данных родителей дают возможность определить, что большая часть родителей высказываются за снижение физических нагрузок и использование вместо привычных учебников планшетов и ридеров.

Однако в противовес полученным результатам бытует мнение о том, что отказ от бумажного варианта учебников повлечет за собой не только обратный эффект в виде возрастающей нагрузки на глаза детей, но и серьезные экономические затраты, что станет крайне невыгодным для общеобразовательных учебных заведений. При этом рост экономических затрат зачастую связывают с дороговизной процесса оцифровки учебно-методической литературы, высокой стоимостью разработки электронных учебников и т. д.

Учитывая вышесказанное, не отметить, что в новой редакции Закона об образовании сказано, что с 1 января 2015 года российские издатели обязаны выпускать только те учебники, которые имеют электронную версию для планшетов, а учителя отныне имеют возможность выбирать, каким из них пользоваться на уроках [3].

Российская Академия Образования, Федеральный Институт Развития Образования, Издательства «Первое сентября», «Просвещение», «Русское слово», «Бином», «Дрофа»и другие задействованы в процессе создания электронных учебников.

В 2015 году свыше 135 тысяч преподавателей общеобразовательных школ из 83 субъектов России использовали возможности электронной формы учеб- ников издательства «Просвещение». Электронные учебники названного издательства успешно прошли педагогическую и общественную экспертизу и 15 мая 2015 года получили положительные экспертные заключения Минобрнауки России. Таким образом, в Федеральный перечень было включено 408 электронных учебников издательства «Просвещение», в числе которых 5 новых учебников по истории России для 6-10 классов [4].

Переход на электронные учебники это один из аспектов программы информатизации общеобразовательных школ.

Яркими примерами внедрения программы информатизации в общеобразовательные школы можно назвать проект «Школьная карта», «Электронный кошелек», «Электронный дневник».

Проект Татарстана «Школьная карта» был признан лучшим и получил первое место в номинации «IT в образовании» на Всероссийском конкурсе проектов региональной и муниципальной информатизации «ПРОФ-ІТ» в 2015 году.

Суть проекта «Школьная карта» заключается в том, что школьники младших классов обеспечиваются яркими браслетами с микрочипом PayPass, а учащиеся с 5 по 11 классов - бесконтактными пластиковыми картами. Подобные устройства дают возможность родителям при помощи личного кабинета на портале госуслуг не только контролировать посещение учащимися основных занятий, но и занятий дополнительного образования. Помимо этого благодаря «Школьной карте» можно осуществлять контроль над такими важными функциями, как оплата проезда в транспорте, школьное питание (вплоть до меню), прочие денежные расходы учащегося, получение книг в школьной библиотеке. Включенное банковское приложение облегчает работу системы «Школьная карта». Установленные в каждой школе терминалы «Электронное правительство» устраняет проблемы родителей, связанные с пополнением школьной карты денежными средствами.

Проект «Школьная карта» внедрен в 63 школах Набережных Челнов, 12 школах и 19 учреждениях дополнительного образования г. Зеленодольск, в 33 общеобразовательных школах 
г. Нижнекамск. В перспективном плане намечено проведение автоматизации в 102 школах в 7 районах республики Татарстан путем внедрения проекта «Школьная карта».

Проекты «Электронный кошелек» и «Электронный дневник» имеют узкоспециализированное предназначение. «Электронный кошелек» позволяет осуществлять контрольную функцию над денежными расходами учащегося (оплата питания, проезда в общественном транспорте и пр.), а «Электронный дневник» облегчает контроль родителей за успеваемостью учащихся.

Однако, все вышеперечисленные проекты, реализуемые в рамках информатизации образовательного процесca, не затрагивают один из важнейших вопросов, суть которого заключается в переходе общеобразовательных школ на электронные учебники.

В России к настоящему моменту проведена апробация ряда масштабных проектов. В их числе «1 ученик: 1 компьютер», «Единая система образования», «Московская электронная школа» и др. При этом имеются положительные примеры применения электронных учебников в образовательном процессе школ.

Реализация пилотной стадии Программы «1 ученик: 1 компьютер» началась в 2013 году в г. Уренгой в МБОУ СШ № 1. В течение 2013-2014 учебного года была выстроена такая образовательная ситуация, в которой портативный нетбук, связанный с компьютерами других учащихся и компьютером учителя по локальной сети. Создание цифровых объектов, применение информационных технологий позволило существенно улучшить эффективность обучения. Одним существенным недостатком Программы является привязка информационных носителей к локальной сети, что снижает мобильность учебного материала, которым могут пользоваться учащиеся.

Помимо представленного выше примера реализации Программы «1 ученик: 1 компьютер» в г. Уренгой, можно отметить положительный опыт внедрения в образовательный процесс подобной программы в 5 школах Республики Татарстан в 2012 году [5].

Следующим масштабным проектом стала «Единая система электронного образования». Названный проект внедрен в Свердловской области в сентябре 2017 года. Основной целью реализации этого проекта стал перевод образовательного процесса на электронные учебники.

Немаловажным по масштабности внедрения и финансирования можно назвать проект «Московская электронная школа». В рамках этого проекта уже треть московских школ переведена на электронные учебные материалы. К концу 2018 года планируется присоединение к проекту еще двух третей оставшихся школ [6].

В 2014 году 4 общеобразовательные школы Краснодарского края осуществили полноценный переход от бумажных учебников к электронным, которые загружены в планшеты. Загрузка учебной литературы осуществляется по почте через Интернет. В качестве библиотекаря, в данном случае, выступает школьный компьютер.

Как и любое новшество, Проекты и Программы внедрения электронных учебников в учебный процесс общеобразовательных школ вызывают ряд обсуждений и дискуссий как среди экспертов, так и в обществе. Положительные и отрицательные отзывы о данном нововведении очень разнообразны [7].

К примеру, О.А. Ладынина и С.В. Алехасин [8] отмечают, что если рассматривать вопрос с правовой точки зрения, то в данном случае у опрашиваемых респондентов и экспертов преобладает мнение, что процесс информатизации обучения и переход к электронным учебникам нет необходимости подвергать государственному регулированию. В данном вопросе нужна государственная поддержка, позволяющая выровнять в правах бумажные и электронные учебники. Это позволит нормативно определить право учащегося пользоваться электронной формой учебников.

О.А. Ладынина и С.В. Алехасин отмечают, что в ходе проведенного опроса учителями школ Москвы, СанктПетербурга и других городов России, участвующих в Проектах перехода на электронные учебники, отмечена высокая мотивация учащихся, повышается самостоятельность учеников, оптимизируется нагрузка учащихся, увеличивается интенсификация учебного процесса, 
вырабатываются новые компетенции учеников, электронный учебник не сложен в использовании [8].

Проведение исследований, позволяющих выявить положительные и отрицательные стороны реализации проектов внедрения электронных учебников и замену бумажных учебников планшетами и/или ридерами, проводилось неоднократно усилиями Министерства образования РФ, научных деятелей, а также специализированных площадок для проведения опросов населения РФ.

Так, например, по сведениям Министерства образования РФ для перехода к электронным учебникам созданы условия для 1,8 млн учеников, при этом на приобретение необходимого школьного оборудования потрачено свыше 64 млрд руб. Помимо этого осуществлено обновление программного обеспечения, расширены возможности школьного интернет-трафика. Названные мероприятия позволили добиться роста успеваемости учащихся, повышения качества образования, что положительно оценивает развитие информационной образовательной среды $[9,10]$.

Выявленные подобные факты, доказанные в процессе апробации положительные эффекты от внедрения электронных учебников, ставят важнейшую задачу - расширение масштабов внедрения электронных учебников в учебный процесс общеобразовательных школ.

Однако, немаловажно отметить и имеющиеся недостатки внедрения электронных учебников в образовательный процесс Российских школ. Как показали результаты опроса, учителя отмечают следующие отрицательные черты: увеличение нагрузки на психику и зрение; недостаточная готовность учителей к работе в новом формате; нехватка персональных компьютеров в общеобразовательных школах; проблемы, связанные с использованием интерактивных приложений по причине неполадок в локальной сети или из-за недостаточной скорости интернета [11].

Корпорация «Российский учебник» отмечает, что в России к 2018 году свыше 1 млн школьников переведено на обучение по электронным учебникам [12].

Несмотря на то, что внедрение электронных учебников является не новой идеей и проходит масштабную апробацию в некоторых территориальных частях Российской Федерации, признать максимальную широту охвата этого проекта нет возможности, что показывают результаты опроса, проведенные усилиями Дневник.ру. В названном опросе приняли участие более 19 тыс. родителей, 36 тыс. учеников и свыше 300 учителей из 85 регионов страны [13]. Как показали результаты проведенного опроса в данное время использование планшетов или ридеров в школах Российской Федерации редкость. Это отметило подавляющее большинство опрошенных родителей (90\%), учителей $(81 \%)$, и учеников $(88 \%)$.

Главными проблемами внедрения электронных учебников в учебный процесс общеобразовательных школ России можно назвать следующие:

- отсутствие денег, которые необходимы на обеспечение общеобразовательных школ необходимым количеством планшетов или ридеров при незначительной стоимости программного комплекса электронной формы учебников [14];

- немаловажная проблема, выявленная Академией повышения квалификации преподавателей, заключающаяся в отсутствии желания и неготовности учителей переходить на новый формат обучения по электронным учебникам;

- профанация идеи. Выявлены случаи, когда преподаватели используют электронные устройства лишь во время открытых уроков, которые посещают проверяющие органы. Таким образом, закупка технологических инноваций происходит лишь для отчета;

- усиленное лоббирование бумажных учебников производителями этого продукта.

Поднимая злободневный вопрос об отсутствии недостаточности средств на переход к электронным аналогам бумажных учебников и выявив опасения ряда специалистов, указывающих на высокую стоимость подобного мероприятия, авторы статьи решили сравнить затраты на бумажные учебники и учебники в электронном виде, которые можно было бы использовать в начальных классах. Целевая аудитория школьников была определена не случайно. Как сказано выше, именно эта категория 
учеников в большей степени подвержена риску осложнений заболеваний позвоночника из-за недопустимого веса ранцев, школьных сумок и пр.

Изучив информационные источники, отражающие объективную оценку средней стоимости одного электронного учебника, авторы статьи отмечают, что сравнивать стоимость электронного учебника с учебником на бумажном носителе даже нет смысла, так как стоимость выпуска одного электронного учебника влечет за собой множество затрат, которые в конечном итоге определяют цену от 600 тысяч до одного миллиона рублей за одно наименование [15].

Однако, есть достойная альтернатива, которая может быть активно применена во множестве школ. В качестве подобной альтернативы авторы статьи предлагают применение учебников в электронном виде, которые можно загрузить на ридеры. Как было отмечено выше, с 1 января 2015 года все издательства, выпускающие учебно-методическую литературу, должны выпускать только учебники, имеющие электронные версии [16]. Это требование регламентируется Законом об образовании [17].

Проведенные исследования позволили определить, что среднестатистическая стоимость учебника в электронном виде составляет не более 60 руб.

Для того, чтобы определить экономический эффект от замены бумажных учебников на электронные, авторы вы- брали в качестве объекта исследования начальные классы общеобразовательных учебных заведений МО г. Новороссийск.

С целью выявления эффективности замены бумажных учебников на учебники в электронном виде, проведено сравнение затрат (рисунок).

В ходе определения затрат, учтена среднерыночная стоимость ридеров, которая в России образовалась в пределах пяти тысяч руб. Учтено также, что в среднем срок полезного использования ридеров - 5 лет. Для упрощения представления результатов расчета и чистоты эксперимента применена примитивная модель традиционного прогнозирования, которая предполагает изменение событий при неизменных прочих условиях.

Как видно на рисунке, несмотря на то, что в первом году переход на учебники в электронном виде предполагает убыток в размере 47 945,900 тыс. рублей, преобладание суммарной выгоды за последующие четыре года составит 82 366,84 тыс. рублей, что дает основание предположить экономическую эффективность предлагаемой альтернативы.

\section{Выводы или заключение}

Таким образом, резюмируя проведенное исследование можно отметить, что выявленная экономическая эффективность перехода общеобразовательных учебных заведений на учебники в электронном виде позволяет достаточно быстро обеспечить окупаемость

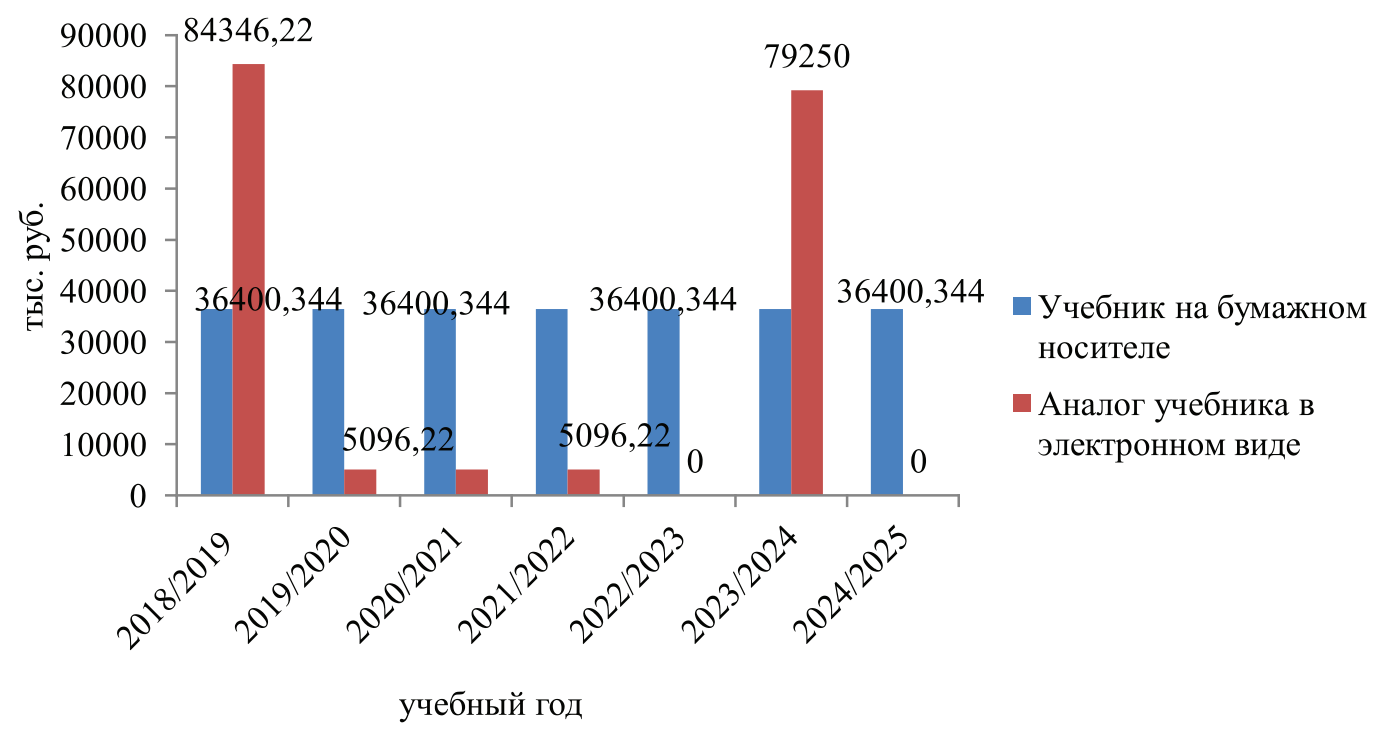

Сравнение затрат на учебники на бумажном носителе и учебники в электронном виде 
затрат, которые необходимо будет осуществить. Подобный вариант имеет явное преимущество над вариантом внедрения дорогостоящих электронных учебников. Особенно, если учесть то, что полный переход на электронные учебники сложно осуществить на современном этапе, из-за того, что нет приемлемой нормативно-правовой базы, имеется достаточно высокий уровень затрат, которые необходимо осуществить на разработку и апробацию электронных учебников.

Поскольку устранение имеющихся недостатков внедрения электронных учебников займет достаточно длительный промежуток времени, предлагаемый авторами статьи вариант внедрения учебников на электронных носителях позволит в короткие сроки решить множество проблем, как экономических, так и социальных.

\section{Библиографический список}

1. Гаджет вместо стопки учебников: для всех или для богатых? - 07.09.2017 [электронный pecypc]. - URL: https://www.zakonia.ru/theme/gadzhet-vmesto-stopki-uchebnikov-dlja-vsekh-ilidlja-bogatykh.

2. ГОСТ Р 57724-2017 [Электронный ресурс]. - URL: http://docs.cntd.ru/document/1200156826 (дата обращения 08.02.2019).

3. Хакимова Л. Как гаджеты и технологии завоевывали школу [электронный ресурс]. - URL: https://mel.fm/tekhnologii/3562489-gadget (дата обращения 07.02.2019).

4. Издательство «Просвещение» завершает апробацию электронных учебников [электронный pecypc]. - URL: http://grozny-inform.ru/news/society/60724/ (дата обращения 08.02.2019).

5. Аналитический доклад «Результативность программы «1 ученик: 1 компьютер» в школах Республики Татарстан». - М., 2014. - 74 с.

6. Власти внедрят проект «Электронная школа» во всех школах Москвы [Электронный ресурс]. URL: http://tass.ru/obschestvo/4621446 (дата обращения 08.02.2019).

7. Электронные учебники: хорошо или плохо? [Электронный ресурc]. - URL: https:// educationmanagers.ru/shkoly/modernizaciya/elektronnye_uchebniki_horosho_ili_ploho/.

8. Ладынина О.А. Будут ли в российских школах электронные учебники? Общественное обсуждение результатов апробации / О.А. Ладынина и С.В. Алехасин // Управление образование: теория и практика. - 2012. - С. 12-16.

9. Российская школа готовится к повсеместному введению электронных учебников [Электронный pecypc]. - URL: http://expert.ru/ural/2014/36/gadzhet-na-vashu-golovu/ (дата обращения 09.02.2019).

10. Электронные учебники для школьников, за и против [Электронный ресурc]. - URL: https:// schoolcard.pro/blog/?p=183 (дата обращения 09.02.2019).

11. Сюзяева С.Ю. Опыт внедрения в учебный процесс электронной формы учебников. - Лакинск, 2012. - 12 с

12. Какой учебник выбрать: электронный или бумажный [Электронный ресурc]. - URL: http:// www.mk.ru/social/2018/03/26/kakoy-uchebnik-vybrat-elektronnyy-ili-bumazhnyy.html (дата обращения 08.02.2019).

13. Ситуация по России: электронные учебники в школах [Электронный ресурс]. - IURL: https:// newtonew.com/school/e-books-at-russian-schools

14. Электронные учебники для школьников, за и против [Электронный ресурc]. - URL: https:// schoolcard.pro/blog/?p=183 (дата обращения 08.02.2019).

15. Электронный учебник за миллион рублей. Директор Росучебника о будущем школ [Электронный ресурс]. - URL: https://www.m24.ru/articles/Segodnya/04092017/150658?utm_ source $=$ CopyBuf?utm source $=$ CopyBuf (дата обращения 09.02.2019).

16. Все российские школы перейдут на электронные учебники [Электронный ресурс]. - URL: https://rg.ru/2013/09/30/uchebniki-site.html (дата обращения 09.02.2019).

17. Федеральный закон «Об образовании в Российской Федерации» от 29.12.2012 №273-Ф3 (последняя редакция) [Электронный ресурс]. - URL: http://www.consultant.ru/document/cons_doc_ LAW_140174/(дата обращения 09.02.2019). 